Jasmina M. Lazić*

Colaboradora externa del Centro

UDC

de investigación de la literatura y del arte

821.163.41:929 Rakić M.

$821 ' 25$

DOI

https://doi.org/10.18485/analiff.2016.28.1.15

\title{
LAS IDEAS TRADUCTOLÓGICAS DE MITA RAKIĆ
}

Our objective in this paper is to present the traductological ideas of Mita Rakić (1846-1890), a member of the Serbian intellectual society, writer, philosopher, translator of several foreign languages, and translator of republican writers such as Victor Hugo and Emilio Castelar in the Serbian culture. In the first part of the paper we present the context in which Mita Rakić works by means of bibliographic references; and then we will expose his traductological ideas given in the preface of the "History of the intellectual development of Europe" of John William Draper.

Key words: critics and theory of translation, Mita Rakić, linguistic criticasters, textual gender (scientific, philosophical, literary) in translation.

\section{Sobre Mita Rakić: su biografía y su posición filosófica e intelectual}

Para acercarnos a la trayectoria biográfica de Mita Rakić, escritor serbio, filósofo, traductor y funcionario estatal, nos ayuda la Enciclopedia popular serbo-croata-eslovena [Narodna enciklopedija srpsko-hrvatskoslovenačka] dirigida por Stanoje Stanojević. La referencia biográfica sobre Mita Rakić está escrita por el famoso historiador serbio del siglo XIX Slobodan Jovanović. Según él (1928:799), Mita Rakić nació el 15 de noviembre de 1846 en Mionica, en la región de Valjevo, y murió el 5 de marzo de 1890 en Belgrado. Fue secretario del Ministerio de Asuntos Interiores bajo el gobierno de Čumić y editor de la revista Vremel que defendía las ideas

*_jasminalazic75@gmail.com

1 Según la historiadora Milanović (2006:145) la revista Vreme empezó su publicación en el año 1874, y terminó el 11 de enero de 1875. La referencia bibliográfica para esta revista se encuentra en: La bibliografia serbia, hemeroteca 1768-2005, [Srpska bibliografija, periodika 1768-2005], Beograd, Narodna biblioteka, 2011, p. 375, en la cual figura que Rakić, además de encargarse de la publicación, también fue editor. 
políticas de dicho gobierno. En el período desde 1881 hasta 1885 ejerció su trabajo en el Ministerio de Asuntos Exteriores hasta ascender a encargado de departamento. En abril de 1885 regresó al Ministerio de Finanzas como ministro bajo la dirección de Hristić, cargo que ocupó hasta el mes de octubre de 1888. Pese a estos detalles biográficos, la mayor ventaja de Mita Rakić fue su conocimiento de varios idiomas extranjeros. Entre todas sus traducciones se destacan: La historia del desarrollo intelectual de Europa [History of the Intellectual Development of Europe] de John William Draper (en dos volúmenes: 1871 y 1873), Las ideas [Ideen] de Henrich Heine (1877), y Los Miserables [Les Misérables] de Víctor Hugo (1866). Estas primeras obras nos demuestran que al comenzar su carrera de traductor, Mita Rakić traducía desde el inglés, el alemán y el francés.

Además de estas traducciones, la obra que más destaca las traducciones y la filosofía de Mita Rakić ha sido la monografía de Andrija B. Stojković bajo el título El desarrollo de la filosofía en los serbios [Razvitak filozofije u Srba (1801-1944)], en la cual dicho autor (1972:177) además de mencionar las convicciones políticas de Rakić (primero socialista, luego progresista) y sus funciones estatales, le presenta como un intelectual, políglota, dedicado plenamente a la labor educacional, y el miembro de la Sociedad intelectual serbia. Por otra parte, esta monografía considera a Rakić como un filósofo que aboga por la corriente del materialismo científico perteneciente a la organización de Omladina [Juventud]. Sin embargo, lo que sobresale en la presentación de Rakić, en palabras de Stojković, es que dicha persona contribuyó de modo significativo a la cultura serbia con sus traducciones.

En cuanto a la bibliografía de Rakić, percibimos que no se trata sólo de la bibliografía usual, sino más bien de una forma de pensar y de ver el mundo. Lo que encontramos en el Apéndice de Homenaje a las personas ilustres en el pueblo serbio de la época más nueva (1888, 1901) [Dodatak Pomeniku znamenitih ljudi u Srpskoga naroda novijeg doba $(1888,1901)]$ de Milan Milićević, son los detalles la vida académica de Mita Rakić quien después de terminar el bachillerato y la Escuela de Estudios Superiores [Visoka škola] en Belgrado, prosiguió su formación en Munich, Zurich, Gotinga, y Londres. Regresó a su país en 1871 para ser profesor sustituto en el bachillerato de Šabac. El 30 de enero de 1872 le eligieron como 
miembro de la Sociedad intelectual serbia. Milićević expresa el conocimiento de Rakić con respecto a las lenguas extranjeras así como de su obra literaria en su lengua materna:

Rakić aprendía con mucha facilidad las lenguas extranjeras, no tanto para hablar, sino para leer a escritores famosos. Aprendió el inglés para poder traducir a Draper; español para poder leer a Castelar; polaco y ruso por el amor a algunos escritores de esas culturas. Conocía muy bien el espíritu y las leyes de la lengua serbia; su sintaxis y su ortografía, con su determinación y consecuencia, superan a casi todos nuestros escritores actuales. Podría ser errónea alguna regla gramatical de Rakić, pero lo literario en él, siempre se ejercía sin tachadura alguna. (MILIĆEVIĆ, 1901:140) ${ }^{2}$

Inmediatamente después de su regreso de Londres, Rakić tradujo la Historia del desarrollo intelectual de Europa [Istorija umnoga razvitka Jevrope] $(1871)^{3}$ con la cual consiguió el reconocimiento en los círculos educativos y científicos del Reino de Serbia. El ministro de la educación en esta época, Stojan Novaković, hizo un comentario en el prefacio [Referat] sobre su traducción del inglés:

Mi opinión no puede ser la de un experto. De esto me esconde aquel hecho que el escritor, perteneciendo él mismo a la gente de bellas letras que ejercen una labor estatal, y enriqueciéndonos con la traducción de una de las mejores historias culturales, puede garantizar, ante los más cercanos de esta profesión, su elección. (NOVAKOVIĆ, 1877:VI)

Así que el nombre de Rakić aparece por primera vez a finales del siglo XIX y tiene un gran impacto en los círculos científicos e intelectuales. La traducción al serbio de la Historia del desarrollo intelectual de Europa emerge relativamente pronto, después de su publicación en el año de 1863 en Nueva York, edición de Harper and Bazar. ${ }^{4}$ Para entender la

2 Todas las traducciones de las citas son de la autora de este artículo.

3 History of the intelectual development of Europe, John William Draper, impresa en la imprenta estatal en Belgrado en 1871 (tomo I), 1874 (tomo II). Publicada por la Sociedad intelectual serbia. Traducción del inglés de Mita Rakić.

4 Se puede anotar que el libro tuvo mucho éxito, en base a las ediciones consecutivas. La casa editorial Bell and Dadly lo publica en 1864, luego George Bell and 
importancia de Draper en aquella época, nos serviremos de las palabras de Rakić, que tiende a explicar no sólo la relevancia de este libro científico y químico, sino también del contexto histórico:

El período de 1830 hasta 1870 se puede llamar la época de la historia de la ciencia. Ésta ha empezado con el descubrimiento de la electricidad y ha terminado con la luz eléctrica. La mitad de la época se caracteriza por la aplicación de la química en la fisiología, una revolución científica que cambió la forma de practicar la medicina. En esta época hay numerosos descubrimientos importantes como: la fotografía, el telégrafo, el transporte ferroviario, y el transporte de ultramar. Estos descubrimientos afectaron tremendamente al desarrollo intelectual y las condiciones sociales. (RAKIĆ, 1874:XVIII)

A la vez, Rakić hizo énfasis a base de la cual se podía intuir el motivo de su traducción posterior del filósofo, escritor, ensayista, y político español Emilio Castelar, puesto que hablando de los cambios intelectuales y sociales, advirtió:

Entre todas [las novedades], la mayor será que gracias al desarrollo y la divulgación de la ciencia, y con la más rápida e incesante comunicación entre los pueblos, se van a determinar las ideas liberales en la política y las elevadas en la religión. (RAKIĆ, 1874:XVIII)

Para Mita Rakić fue muy importante su participación en el movimiento de Omladina [Juventud]. Este agrupaba a los intelectuales y otras personas destacadas a finales del siglo XIX que principalmente se ocupaban de la liberación de los pueblos sur-eslavos de la Monarquía Aus

Sons en 1875, 1884, 1881, 1905, y terminando en 1914. Los datos han sido tomados desde el catálogo principal de la Biblioteca Nacional Británica, consultada el 2 de diciembre de 2014:

http://explore.bl.uk/primo_library/libweb/action/search.do?dscnt $=0 \&$ scp.. scps $=$ sc ope $\% 3$ A $\% 28$ BLCONTENT\%29\&frbg=\&tab=local_tab\&dstmp $=1417981160654$ $\& \mathrm{srt}=\mathrm{rank} \& \mathrm{ct}=\mathrm{search} \& \operatorname{mode}=\operatorname{Basic} \& \mathrm{vl}(488279563 \mathrm{UIO})=$ any $\& \mathrm{dum}=$ true $\& \mathrm{tb}=\mathrm{t}$ \&ind $x=11 \& v 1($ freeText 0$)=A \% 20$ History $\% 20$ of $\% 20$ the $\% 20$ intellectual $\% 20$ development $\% 20$ of $\% 20$ Europe $\% 2$ C \% 2 e 0 Draper $\% 2$ C $\% 20$ John $\% 20$ William $\& \mathrm{fn}=$ search\&vid=BLVU, Esta consulta no excluye la posibilidad que habrán más publicaciones. 
tro-Húngara y del Imperio Otomano. Jovan Skerlić (1906:252), el crítico literario más prestigioso de esta época, describe a Mita Rakić como un prominente miembro de Omladina [Juventud], quien traducía a Víctor Hugo, y que publicó su traducción de Jadnici [Les Misérables] al serbio en 1872. Sin embargo, la perspectiva de la cual parte Skerlić en cuanto a la traducción de Hugo es la perspectiva "republicana", es decir la idea que Víctor Hugo era el orgullo de la democracia europea. Con colorido y vivacidad, Skerlić lo explica:

Víctor Hugo, "el gran desterrado“, quien luchó al lado de Jersey contra Napoleón, se proclamaba como el poeta de Los castigos, el percusor y el orgullo de la democracia europea. Era el líder natural del romanticismo francés y el profeta de la democracia contando entre sus admiradores los románticos y patrióticos miembros de Omladina serbia. Sus novelas traducidas tenían un alto impacto social. En el año de 1862, el diario belgradense de "Trgovačke novine“" [La prensa comerciante] aporta un artículo de un diario húngaro: Víctor Hugo, un desterrado y educador del pueblo. El mismo diario aporta su Očajnike, que no son otra cosa que Les Misérables, que aparecieron el mismo año en Bruselas. El diario "Srbski dnevnik"[El diario serbio], publica en el año de 1864 "una nota característica según Hugo", sobre el obispo Myriel y el encarcelado Jean Valjean, un episodio traducido de Jadnici. En 1872 Mita Rakić publica la traducción completa de Jadnici. (SKERLIĆ, 1906:252)

Por una parte, la importancia de las ideas universales se reconoce entre los pueblos más pequeños. Por otra, la prensa es un trasmisor de ideas universales mientras ayuda a estar al corriente. Sin embargo, lo que se puede anotar de la descripción de Skerlić es que Očajnici en el diario belgradense "Trgovačke novine" podría contener errores de traducción, por lo menos en el título, pero no en la divulgación de las ideas. Estos hechos fueron estímulantes para que aparecieran las traducciones completas de los pensadores franceses. Skerlić indirectamente señala que la traducción de Rakić es una traducción precisa y distinguida, bajo el título de Jadnici en comparación con otros intentos, sin llegar siquiera a mencionar a sus traductores. Esta descripción corresponde con el postulado traductológico "quien traduce", es decir "de qué autor es la traducción". Por una parte, la autoría de la traducción, y por otra la idea contenida en dicha traducción. Así, Rakić es distinguido no sólo como traductor sino como republicano francés. Skerlić (1906:253) percibe con audacia que después de la 
traducción de Hugo, continúa la lista de sus traducciones "de los escritores republicanos“: Jules Simon: Škola [L’École] en la revista Vila (1886), Domaća sloboda [La Liberté], en la revista Srbija (1867), Parnica braće Neila [L'Affaire Nayl] en la revista Danica (1869-1870), Nešto o slobodi [La Liberté de conscience] en la revista Radnik (1871). Rakić también traduce a Eugenio Pelletan: Matí [La mère] en la revista Danica (1869) y Pogled na svezu između nauke, [Un regard sur la connexion entre les sciences] lo que hizo Dimitrije Matić en la revista Glasnik Društva Srbske Slovesnosti. Como vemos, Rakić traduce las ideas que deben influir en las tendencias educativas y científicas no sólo en la literatura sino también en la cultura serbia. Éste es el ambiente en el cual, como lo revela Skerlić, Rakić traduce a Emilio Castelar. Pese a la influencia ideológica alemana en las bellas letras durante la cumbre de las ideas románticas, especialmente la del poeta Henrich Heine, se destaca Emilio Castelar. De ahí proviene el comienzo de la traducción de obra de Castelar en cultura serbia, tanto por Rakić como por Savković.

Atenta tanto al movimiento de los republicanos italianos como al de los franceses, la organización Omladina siguió también a las luchas de los republicanos españoles, en particular a su gran orador Emilio Castelar. Su discurso célebre De los derechos de hombre, celebrado en la sesión de las cortes constitucionales del 13 de junio de 1869, en la revista Zastava (traducidas por Svetozar Savković). En la misma revista, Savković tradujo El discurso de la libertad de la coinciencia y el Catecismo republicano (1872), impreso en la edición especial. En la revista Radnik (1870-1871) se encuentra El discurso de la libertad religiosa. La oratoria de Castelar y su alto idealismo parecen creados para nuestra generación, a la cual le gusta la política literaria y la literatura política. (SKERLIĆ, 1906:253)

Skrelić concluye:

Los revolucionarios italianos, especialmente Mazzini, los liberales franceses, y los republicanos ideológicos del fin del segundo imperio, entre ellos Eduardo Laboulaye, Víctor Hugo, y el republicano español Emilio Castelar han sido los maestros democráticos de nuestra Omladina. (SKERLIĆ, 1906:254)

En 1869, Rakić terminó su traducción de la Población Republicana [Narodni ljudi] de Emilio Castelar, publicada en 1870. La advertencia 
de Skrelić de que Rakić pertenecía a una generación que "le gustaba la política literaria y la literatura política“ es pertinente a Skrelić mismo y a su labor crítica, que proviene de su tesis doctoral en la cual trató el tema de lo socio-político en la literatura. ${ }^{5}$ Creemos que Rakić como filósofo y escritor, traducía a Castelar porque en su obra encontraba ideas similares y contemporáneas de lo que ocurría en su entorno de trabajo. Gracias a sus traducciones, Rakić quiso contribuir al desarrollo intelectual en su comunidad, que apoyaba una orientación democrática y liberal en la sociedad serbia.

Cuando Milićević cita todo lo que Rakić tradujo, nos muestra un abanico de sus intereses, que tienen, además del carácter literario, un reto científico-educativo y socio-ideológico. Milićević (1901:140) indica que el 24 de enero de 1887 el presidente del Consejo de educación del Ministerio de Educación le preguntó a Rakić en una carta cúales fueron sus obras literarias. Rakić le respondió el 27 del mismo mes con otra carta clasificándolas de manera temporal:

1864 El disparo del fusil - un cuento, la traducción del inglés

1864 La crítica sobre Eva, la bella - una novela de Meri

1865 Kaldarija - un cuento del mauro Joakije, traducción

1865 Veinte millones - un cuento de M. Hatman, traducción

1866 Karan, un cuento de M.Joakije, traducción

1866 Sobre la educación feminina, de Virchow

1866 Sobre Santo Atos y Hilandar, traducción del ruso

1867 La nariz, un cuento de Gogol

1867 Angela de Zagor, una novela, traducción del polaco

1868 La fuerza y la materia, de Luis Büchner (en Matica)

1868 De la economía política, de Keri, traducción del inglés

1868 La ciencia y su método, de Keri

1870 La historia del desarrollo intelecutal de Europa, de Dreper, el

vólumen primero; $y$ en

1873 el vólumen segundo de la obra misma.

1873 El movimiento republicano en Europa, de Emilio Castelar, traducción del español

1874 Vreme, el diario político

$5 \quad$ Según Ković (2014:467) la tesis doctoral de Skerlić se titula La opinión pública en Francia hacia la poesía social y política desde 1830 hasta 1848, defendida en francés en 1901. 
1875 Impuestos, una serie de estudios de finanzas

1876 El camino serbio de Mac-Yver, traducción del inglés

1876 Por Serbia, de Víctor Hugo

1877 Ideas de Henrich Heine

1877 Una hoja de la física social

1879 Ataman Kunicki, de Czajkowski, del polaco

1879 Termolama, de Czajkowski, del polaco

1879 Dede-Sultan, un cuento histórico de Jovan Šer

1879 La población republicana, de Emilio Castelar, del español

1879 De Inglaterra, de Henrich Heine

1879 La historia verdadera, de Víctor Hugo

1879 De Nueva Serbia, 16 estudios geopolíticos, etnográficos e históricos

1880 De Italia, de Heine

$1880 \mathrm{El}$ arte y la ciencia, de Víctor Hugo

1880 La reina de Saba, un cuento, del francés

1880 Los aforismos políticos

Dos apartados nuevos de Solomón

1881 Contra los estafadores políticos

1881 Para un soldado, de Víctor Hugo

1881 La libertad de la prensa, un estudio político

1881 La religión y la ciencia, los aforismos en el Vesnik cristiano

1881 La ley de la prensa libre

1882 El parlamento y el presupuesto

1886 Los miserables, la novela de Víctor Hugo en elveinte cuadernos.

En base a esta bibliografía de traducción se puede anotar que Mita Rakić tiende a introducir ideas progresistas. La orientación filosófica de Rakić se interpreta como científico-positivista. Uno de los libros clave de este ámbito es su obra Una hoja de la física social (1877).

En este libro, Rakić sigue al científico positivista belga Adolphe

6 Es interesante el comentario mismo de Rakić en cuanto a la ley de la libertad de la prensa, como lo cita Milićević (1901:141): "Se hace muy evidente - dice Rakić en la carta: que añado la ley sobre la libertad de la prensa del 12 de marzo de 1881a mi obra [literaria y de traducción]. El señor presidente, cuando era necesario ser orgulloso por ello, todos los ministros y todas las cabezas se apropiaron de la ley; sin embargo, hoy cuando ésta se anula, cuando cada uno se escapa de ella, cuando toda la miseria se echó a su redactor, es conveniente que lo abrace como si fuera mi niño, puesto que la ley lo es, de veras, de al pie de la letra, excepto una palabra sabía de los dos abogados relevantes de aquel tiempo. 
Quételet y su libro La física social o el desarrollo de las facultades del hombre en dos tomos (Physique Sociale, ou essai sur le développement des facultés de l'homme, 2 vol.), luego La estadística moral de Inglaterra comparada con la estadística moral de Francía (Statistique morale de l' Angleterre comparée avec la Statistique morale de la France, París, 1864) de André Michel Guerry, el El tratamiento de la fisología humana, estática y dinámica (A Treatise on Human Physiology, Statical and Dynamical, 3 vol.) de Draper y los autores alemanes, entre los cuales destacan Büchner, Vogt, Moleschott, los que difundían ideas "positivistas y mecanicistas de Compte sobre la sociedad“, según Stojković (1972:177). Es evidente que Rakić fue un divulgador de las conceptualizaciones del mecanicismo y determinismo absolutista en cultura serbia. De la estadística y la demografía decía: "es un tránsito natural hacia la física social, que reduce la sociedad libre al mecanismo que regula las leyes mecánicas". Por lo tanto, la voluntad es sólo una expresión necesaria de la condición cerebral, que nace bajo la influencia externa del libre albedrío y de la acción voluntaria independiente de sus influencias, este tipo de voluntad no hay. Stojković (1972:177) se pregunta "si todo es necesario, según las leyes naturales, si el hombre hace todo según la influencia de algunos estímulos que están fuera de su libre albedrío“, ¿eso quiere decir que todo en nuestra vida es determinado de forma fatal? Rakić responde negativamente sobre esta cuestión, porque cree que el hombre, pese a todo, puede elegir entre "aceptar o rechazar todo lo que le atrae y le provoca".

Sobre este tema, Rakić dio una ponencia en Gradska kasina el 10 de febrero de 1876, inmedatamente después de publicar el libro. Novaković hizo un comentario sobre la importancia del empeño de Rakić y su contribución al desarrollo de la ciencia en los serbios:

Esta ponencia no se parece a una ponencia simple. Se trata de un libro completamente terminado, en el cual se expone qué piensan los filósofos y escritores progresistas sobre la sociedad humana como una totalidad orgánica; cómo nació la ciencia, cómo se ha desarrollado hasta hoy, y cómo la humanidad ha ido elaborando e indagando sobre los acontecimientos sociales; y cómo se ha desprendido su importancia y su amplio impacto en nuestro tiempo, alcanzando a cada europeo educado. (NOVAKOVIĆ, 1977:VI) 


\section{Los criticastros lingüísticos de Mita Rakić}

Después de contextualizar la posicion filósofica e intelectual de Mita Rakić, nuestro siguiente propósito es analizar sus ideas sobre la traducción. Como traductor y teórico de la traducción, Rakić intenta defender la posición de la lengua serbia, así que su acercamiento traductológico a la vez abarca varios aspectos de la lengua meta, al cual se traducen los textos. Desde su punto de vista, se trata de la lengua en formación a finales del siglo XIX. Por eso, aparece el problema de las traduciones de nuevos ítems, conceptos, y términos. Rakić denomina "criticastros lingüísticos", a los críticos que le reprochan, es decir, a todos los que piensan que tienen pleno derecho de criticarle sin respaldo. La nota preliminar de Rakić en la Historia del desarrollo intelectual de Europa, se puede leer como una fuente de la indagación crítico-teórica sobre sus traducciones.

En primer lugar, con el uso del término "criticastro," Rakić retoma de la tradición lingüística alemana en la cual él se educó. Con la elección de este término, Rakić sugiere que aun los calcos extranjeros reflejan mejor el significado de la traducción adaptada del término. Por ejemplo, ¿qué sería, si hubiera utilizado el termino "criticón"? Éste se referiría más bien a la crítica no constructiva, al reproche, y no al hecho de "no tener el apoyo, ni fundamento, ni doctrina al censurar y criticar la obra de un ingenio," lo denota este término según la RAE. ${ }^{7}$ En segundo lugar, pero no menos importante, Rakić introduce el aparato terminológico que le va a servir para definir su área y su objeto de la investigacción gracias a las traducciones "palabra por palabra" de los términos extranjeros. En este caso, se trata tanto de la ciencia de la traducción (o traductología y su subrama que podría ser la crítica traductológica) como de la ciencia de la lengua, en la cual los calcos funcionan como un tipo de nomenclatura para establecer nuevos campos científicos. A la vez, nos puede servir de apoyo el pensamiento de Meschonnic (2004:83) según el cual: "la defensa y la extensión del préstamo no son solamente del ámbito de la lingüística“, sino que la poética de la traducción también se funda en su renovación. Según el pensador teórico francés, la poética de traducción es literalmente entendida como una teoría de traducción, es decir, una traductología. Por lo tanto, es entendida como una ciencia en sí misma, separada de la lingüística. La

7 RAE, Diccionario de la lengua española, tomo I, vigésima primera edición, p.598 
traducción es siempre una labor sobre la lengua y sobre los préstamos, en la cual, estos últimos (fraseológicos y sintácticos, no sólo léxicos) tienen su lugar en una indagación teórica.

El término "los criticastros lingüísticos" también se puede interpretar como una metáfora, es decir una forma de pensar sobre la lengua en la que Rakić tiende a establecer su terminología crítico-traductológica. Su terminología es un argumento a favor, desde el punto de vista de Ortega y Gasset (2010:213). Según el filósofo español, la metáfora no es sólo una transposición simple del nombre sino que tiene gran revelancia en la ciencia. Es decir, el término nuevo obtiene su significado por medio del significado antiguo, sin rechazarlo. Por consiguiente, la metáfora, no sólo en la poesía, sino también en la ciencia, representa un elemento constitutivo del pensamiento científico. De esta forma, la metáfora de Rakić de "criticastros lingüísticos" no sólo conduce hacia la denominación de los críticos no competententes respecto a la traducción, sino que también es un término culturológico-traductológico, en base al cual define sus postulados téoricos de traducción y sus cuestiones lingüísticas.

En la nota preliminar de la traducción de la Historia del desarrollo intelectual de Europa- Rakić expuso sus observaciones traductológicas sobre la posiblidad de la lengua serbia, en aquel entonces todavía no normativa, de adquirir y aceptar nuevos términos tanto científicos como filosóficos.

Utilizaba los préstamos donde era obligatorio y con intención. Por eso, muchos me podían criticar. Pero, todos ellos designan los términos puramente filosóficos y técnicos; y que nuestro idioma, en sentido filósofico, no está bien elaborado, no posee denominaciones para ciertos conceptos. El lector de este libro lo va a percibir. (RAKIĆ, 1871:VI, en cursiva J.L.)

Contra la idea de la naturalización, es decir, contra la adaptación de la terminología a la lengua serbia, que en aquel momento todavía se estaba estandarizando, Rakić aboga por las normas, según las cuales, el término debe adecuarse a su denominación de la lengua fuente y no a aceptabilizarse a su denominación de la lengua meta:

Que intente la misma lengua serbia expresar el término en la traducción, pero no aproximadamente, sino con precisión. Y si hubiera algunas expresiones serbias para los términos y conceptos científicos, yo preferiría 
utilizar expresiones prestadas. Porque las denominaciones para los conceptos científicos y los términos técnicos no son una riqueza común de todas las lenguas. Y lo que es común en todas las lenguas, nosotros tampoco lo podemos rechazar. Es más fácil aprender los términos científicos ya hechos, precisamente elaborados que hacer calcos en serbio - iy a donde llegaríamos si se pudieran hacer calcos! (RAKIĆ, 1871:VI).

En cuanto a los calcos, que hacen acceptable el concepto y el sentido de una palabra o una expresión extranjera en la lengua, cultura, ciencia y filosofía meta, Rakić destacó la importancia de encontrar una palabra adecuada. Según él, a veces, mediante la estrategia de naturalización, no se consigue el sentido original del término. Incluso se puede llegar a una confusión sobre el objeto de traducción:

Con hacer calcos no se consigue todo. La denominación serbia necesita ser explicada. Tomemos un ejemplo: mi amigo Kujundžić ${ }^{8}$ denomina inducción con la palabra de espiaje. Sin embargo, si él no explica qué significa dicha palabra, nadie se enteraría que eso es la inducción sino que se refiere al espiaje. Pese que Kujundžić dice que en la inducción actúa de la misma manera que el espiaje, es decir se induce a ciegas, él como filósofo no debe permitir que, tanto la inducción como el espiaje, signifiquen lo mismo en serbio. De misma manera nuestros profesores pensaban que cada niño sabía que significaba kačestvo, puesto que se trata de un término esloveno-serbio. No obstante, cuando uno de ellos le pregunta a un estudiante: ¿qué significa kačestvo? - éste le responde: ¡kačestvo es cuando estoy colgado sobre un árbol! ${ }^{9}$ (RAKIĆ, 1871:VI, en cursiva J.L.)

En una pregunta retórica: “¿no es más práctico evitar tanto esfuerzo y tomar las expresiones ya hechas y definirlas?" revela un grado de la dificultad y de la complejidad del oficio de traducción en cuanto a la incorporación de

$8 \quad$ Milan Kujundžić es el creador de la psicología en los serbios; uno de los primeros profesores en la Escuela Superior hasta el año de 1884, según Stojković (1972:149). Luego le sigue Ljubomir Nedić. Stojković explica que Kujundzić enseñaba según los psicólogos positivistas ingleses, según Lluis, compartiendo este punto de vista con Mita Rakić.

9 Rakić, a través de juego de palabras, utiliza el término ruso "kačestvo" cuyo sentido original es "cualidad" y lo pone en relación fonológica con el verbo serbio "kačiti" cuyo sentido es colgar. De hecho, kačestvo es un buen ejemplo de una expresión idiomática que significa "amigos falsos" entre el ruso y el serbio. 
la nueva terminología filosófica y científica. Él da prioridad a la estrategia de adecuación al texto fuente si se trata de los conceptos y términos filosóficos y técnicos. Desde la perspectiva actual de la traductología, Rakić representa un punto de vista muy moderno' y que coresponde al concepto de la internacionalización de la terminología científica. Sin embargo, se resiste a la elaboración de diccionarios o glosarios en los cuales nuevos términos podrían ser explicados a un público menos experto en dicha materia. Esta actitud no pertenece a la idea positivista de la ciencia por la cual abogaba. Por otra parte, Rakić tampoco es un filólogo, y este hecho puede influir en su excusa. Pese a que manifestó no tener el tiempo, su público debería haber alcanzado un nivel que les permitiría entender las novedades en la ciencia y su nueva términología.

Me decían que era bueno añadir un diccionario de todos los préstamos a este libro. Pero yo no tuve tiempo, tampoco pensaba que sería posible hacerlo simplemente en forma de diccionario. Es decir, interpretar una palabra por otra, o por lo menos, por otras tres palabras. Hay tantos términos, que pese a toda la explicación, quedarían sin ser entendidos a todos aquellos que no hubieran aprendido, por ejemplo, astronomía, química, física, etc. Este libro no ha sido escrito para la gente llana, sino para un público más educado. Lo van a leer aquellos que han terminado la escuela superior. Y si nuestras escuelas superiores no han podido dar, en estos treinta años, tanto conocimiento a sus aprendices para que lean un libro científico - no es mi culpa. (RAKIĆ, 1871:VI, en cursiva J.L.)

Rakić formula su principio traductológico, respecto a la dicotomía traductológica, tan desprendida en el pensamiento teórico; especialmente en la teoría de Schleiermacher, relacionada con la fidelidad de la palabra del texto fuente (es decir, que se trata de la estrategia de extranjerización) o de la fidelidad del sentido del texto meta (que se refiere a la estrategia de domesticación):

Todavía me queda por decir que era un gran honor traducir esta obra. Pero, tenía cuidado de no perjudicar a la lengua serbia, teniendo en cuenta lo de Gogol ${ }^{10}$ : 'En la traducción es importante que nos dirijamos, ante todo, a los pensamientos, y en menor grado a la palabra, aunque las consecuencias sean insólitas'. (RAKIĆ, 1871:VII).

10 Para la traducción del ruso al serbio expreso mi agradecimiento a la investigadora Aleksandra Mančić. 
Por concluir, retomando la idea de Schleiermacher, según la cual cada traductor está ante un problema dialéctico: o va a traer al escritor a una lengua extranjera o va a llevar el lector a un viaje fuera de su lengua, es decir de su hogar. Siguiendo esta orientación estratégica, Rakić optó por traer a Draper a la lengua serbia, de alguna forma domesticarlo, pese al hecho que "traicionó" el texto original en inglés.

\section{EI hereje ortográfico de Mita Rakić}

Rakić cuestiona la ortografía, que es uno de los aspectos fundamentales, especialmente en la época de establecer las normas lingüisticas. La ortografía de cada lengua representa un marco al cual el texto traducido se adopta y se encaja. En este respecto, nuestro intento es demostrar que tanto la historicidad de la lengua como las normas ortográficas están en relación con la teoría de la traducción y que, por consiguiente, su valoración es adecuada. Ivić, el historiador de la lengua serbia, describe el periódo del siglo XIX respecto a la lengua serbia con las siguentes palabras:

El período entre los años cincuenta hasta los años setenta, fue no sólo el de la normatividad gramatical, sino también la época de la elaboración de las posibilidades expresivas de la lengua literaria. Al alcanzar un idioma que no les encorsetaba, los escritores empezaron a investigar con pasión el campo que se extendía ante ellos. (IVIĆ, 1998:239)

En Rakić, la práctica de la traducción es inseparable de la teoría de traducción, como lo menciona Hurtado Albir (1996). Mientras traducía a Gogol, a la vez asimilaba sus observaciones teóricas sobre la traducción.A pesar de su nota preliminar en la traducción de la Historia del desarrollo intelectual, Rakić cambió el tratamiento del lenguaje filosófico y científico al literario. Esto representa una justificación al aporte de Ivić que aseguraba que tanto los escritores como los traductores a finales del siglo XIX contribuían al desarrollo de la lengua literaria serbia. Por esta razón Rakić (1871:IV) dice: “Ante todo, yo no creo en ninguna ortodoxía. Tampoco creo que en cuestion de ortografía en nuestro idioma está determinado para siempre, en todos sus aspectos." Desde una posición crítico-teórica, de alguien que principalmente pertenece a las bellas letras, Rakić hace un 
aporte a las normas, tanto gramaticales como fonéticas, en la lengua serbia durante el período de su estandarización.

La letra "h" es peculiar. No soy un experto en el asunto sólo un simple súbdito en la jerarquía literaria. Siendo eso, me importan directamente todas sus doctrinas; y yo tengo derecho a protestar y rebelar contra todo lo que me parece injusto e inadecuado. Yo protesto contra la imposición de la letra "h". Digo la imposición, porque su sonido no existe en serbio. Admito que [la letra h] estaba en el proto-serbio, pero no acepto su restauración hoy en día, sólo porque existía en antaño, y por que se utilizaba por allí y por allá. Si nuestros filólogos, a los cuales brindo un homenaje, al mismo tiempo fueran los 'filólogos de la lengua' ${ }^{11}$, ellos se encargarían de esta restauración. Ellos mismos admiten que en el habla del este de nuestro pueblo, el sonido "h" no se oye, y que en otros lugares no se pronuncia puramente, sino que se dice "v", en otro lado "k", y en el tercer lugar como "j", y en el cuatro como "g". Los maestros se empeñan en que los niños pronuncien el sonido " $\mathrm{h}$ " - así que éste es extraño en nuestro idioma - y muchos no lo pueden pronunciar como se debería, salvo los que nos entrenamos en esto. No es natural concluir que el sonido "h" está desapareciendo ligeramente en la lengua serbia. ¿Cuándo se va a perder por completo? Y, entonces, ¿no es raro que en vez de los términos bellos y fáciles, se construyan unas palabras insólitas, escribiendo: uda $h$ nuti [respirar], truhnuti [podrir], kihati [estornudar], buzdohan [cabezote], buha [pulga], muha [mosca], kuhati [cocinar], kuhina [cocina], du $h$ nuti [soplar], etc. ${ }^{12}$ ? ¿No se respeta el postulado básico de la ortografía fonética, según el cual: escribe como hablas, es decir, ¿tantas letras, cuantas voces pronunciadas? Tanto los italianos como nosotros tenemos una ortografía fonética. Ellos no tienen la letra "h", así que no la escriben en ningún lugar, salvo en algunas ocasiones - y ahí, se sobreentiende sin ninguna razón - simplemente por su importancia histórica. Por lo menos su gramática enseña que la letra " $h$ " no se debe pronunciar; la nuestra, al contrario, tiende a que esforcemos la garganta, y que la pronunciemos como si fuéramos árabes - como ch. Aunque permitimos que el sonido " $h$ " se pronuncie precisamente en

11 él usa: 'filólogos de la lengua', pero hoy en día nos referimos a los lingüistas.

12 Adjuntamos la norma gramáticamente correcta y normativa de estos términos hoy en día, en ekavica: udahnuti, trunuti, kijati, buzdovan, buva, muva, kuvati, kujna y kuhinja, duvnuti. 
todas las ocasiones en una parte de nuestro pueblo, no podemos dejar que entre en la lengua literaria. Puesto que, en la lengua literaria, hay que elegir aquel dialecto, que resulta más fácil, más redondeado, más elástico, en el cual hay menos voces duras y ásperas. En resumen, aquel dialecto más estético. Por supuesto, el dialecto más bello es el de nuestra habla del este. Ahora si la mayoría o la minoría habla en este dialecto (lo segundo afirman unos pocos que están a favor del habla del sur) - les da igual. El dialecto florentino es el más pequeño, pero es la base de la lengua literaria italiana. ¿Por qué? ¡Porque es más fácil! París, según la población, es una vigésima parte de Francia. Sin embargo el habla parisiense es un modelo para cada francés - porque es más bello. Por último: los proteccionistas de la "h" escriben con esta letra las palabras Hrist (Christ) y Hohenloha (Hohenlohe). La "H" o es "h" o "ch", pero no pueden ser las dos. Si dicen que sí, entonces, que borren la regla: ¡para cada sonido una letra! Y pongámonos de acuerdo. (RAKIĆ, 1871:IV-V).

Defendiendo su regla de no pronunciar, y por lo tanto, no escribir la letra "h", Rakić apela a los ejemplos positivos de la tradicción lingüística occidental, por lo menos a aquellos que no pronuncian esta voz. A la vez intenta dar un lugar significativo a estas reglas en cuanto a la normatividad de la lengua serbia. A pesar que entre los escritores se glorificaba la reforma de Vuk Karadžić, Ivić destaca:

[que] en su idioma literario, Vuk Karadžić, hizo más arcaizante con la introducción de la "h" (luego el grupo de "tj" y "dj" en los ejemplos como tjerati [echar], djevojka [chica] y las peculariedades menores como mnogo [mucho] y sumnja [duda] en vez de mlogo y sumlja), mientras los modelos del habla que encontraba, en mayoría de los casos, fuera de este territorio (en Dubrovnik, en la parte del oeste del antiguo Montenegro y la costa adriática). Eso no significa que él tomó todo esta habla como una base de la lengua literaria; él sacaba prestado dos o tres peculariedades que le permitieron acercar su idioma a la tradición serbia, y que con esto, la hizo más aceptable para el público serbio. (IVIĆ, 1998:224).

Aunque Rakić es un ejemplo de la tradición serbia que no usa y no escribe la letra " $h$ ", la reforma de Vuk Karadžić tenía un gran impacto en el Reino de Serbia en aquel entonces. Gracias a ella, se hizo la estandarización 
de la lengua que fue adoptada por la mayoria de los sureslavos sin importar donde vivían (Imperio Austro-Húngaro o Imperio Otomano). No se debe perder de vista que Rakić escribió su nota preliminar e imprimió su traducción del libro de Draper en 1871, cuando la norma ortográfica estaba establecida y estandardizada, pero no aceptada por completo. A pesar que en el año 1847 fue publicado Rat za srpski jezik i pravopis [La lucha por la lengua y la ortografía serbia] de Vuk Karadžić, en Budapest, todavía existía la resistencia a ese tipo de normatividad. Al establecer ekavica (el habla del este) en vez de ijekavica (habla del oeste) como las normas estandarizadas en el Reino de Serbia en 1847 y aceptarlas por completo en $1898^{13}$ el proceso tuvo oponentes, lo que se puede ver en la obra de Vuk Karadžić Skupljeni gramatički i polemički spisi I-III, 1894-96. [Los escritos gramaticales y polémicos recolectados I-III].

Rakić destaca la importancia de las expresiones y los términos arcaicos, diciendo que se perdieron con la reforma de Vuk Karadžić. ¿Cómo? La reforma de Vuk fue novedosa y revolucionaria para su tiempo, pero tenía sus defensores y sus opositores. Rakić fue su defensor, como lo confirma Ivić (1998:248). No obstante, él exponía sus desacuerdos respecto a algunos aspectos de la reforma. Sus desacuerdos se refieren al uso de las expresiones y términos arcaicos:

En cuanto a los términos arcaicos, los utilizé por obligación, por no tener los términos serbios puros para algunos conceptos, o como expresiones peculiares con el fin de conseguir el colorido bíblico y teólogico. Estas formas arcaicas las utilizamos, en verdad, muy pocas veces, pero siempre a la fuerza. Hay que estar muy atentos al "limpiar" la lengua, llegamos hasta tal punto en que hemos borrado todas las categorías de los términos, y ahora nos parece díficil y complicado sin ellos. En vez de una palabra o una forma de decir, estamos dando círculos y estamos describiendo lo mismo, con tres o cuatro palabras, y de nuevo no hemos dicho lo que se debería haber dicho. Entre los numerosos ejemplos, menciono sólo el participio activo que no se permite cambiar según los casos, en muchas ocasiones, no es tan fácil evitarlo. Yo lo utilizé sólo en aquel momento, cuando me veía obligado. (RAKIĆ, 1871:V-VI).

13 Nejlor, Kenet, Sociolingvistički problemi medju jezicima Južnih Slovena, preveo i priredio Miroljub Joković, Prosveta, Beograd, 1996, p.150 
Ivić apunta que en el período entre los años cincuenta y setenta del siglo XIX se llegó a cambiar el contenido léxico de la lengua serbia, lo que no favoreció a la terminología teológica y eclesiástica. Respecto a la aceptación de los avances en las ideas positivistas del pensamiento contemporáneo de aquella época, las cuales tenían una procedencia culturológica, se consiguió una apertura de la lengua misma, es decir una transformación del léxico en la traducción. Luego vino la época de la propulsión de la lengua serbia hacia las influencias extranjeras, que no fueron principalmente de carácter ruso. Por consiguiente, no es de sorprender que Rakić utilice el término "criticastro", un calco de la lengua alemana.

El cambio de la lengua literaria, realizado como una parte del cambio sustancial en la orientación de la cultura serbia, en la época de Vuk e inmediatamente después de él, se refirió al cambio léxico. Las novedades se relacionaban, ante todo, a los préstamos, mientras las palabras domésticas se quedaban, en general, sin influencia. El cambio impactó más al léxico desprendido y retomado de la redacción rusa del antiguo eslavo. La mayoría de estas palabras desapareció de la lengua literaria serbia. No obstante, algunas lexemas inalteradas han sobrevivido la limpieza, o rechazadas por una temporada, y han vuelto poco a poco a escondidas cuando la presión de los filólogos puristas disminuyó. Lo que es muy evidente es que este tipo de palabras pertenecen a la esfera religiosa y eclesiástica como: žrec [sacerdote], molepstvije [oración] ili dveri [puerta]; o a la esfera moral y psicológica como bodar [alegre], revnost [aplicación], roptati [sufrir], pravedan [justo], nužda [necesidad].... Los ejemplos de estos dos grupos se han usado en dicha forma o alguna similar desde la época de la redacción rusa y serbia del antiguo eslavo hasta la lengua moderna. Sin embargo, hay algunos ejemplos cuando los términos de la lengua eclesiástica no son reconocibles por sus características principales, sino que han sido adoptados a las posibilidades de la lengua serbia: prosvetitelj [educador], zastupnik [representante], žrtva [víctima], beskonačan [infinito], presto [trono], ljubazan [amable], nastavnik [maestro], vaspitati [educar], podvig [proeza], podoban [adecuado]. (IVIĆ, 1998:250-251)

\section{Conclusión}

Todo lo analizado en este trabajo presupone que no se puede indagar sobre la ciencia sin pensar la lengua. No hay desarrollo de la ciencia, ni 
de las ideas científicas, sin el desarrollo de la lengua a la cual las mismas se traducen. El pensamiento de Rakić refleja esta realidad. La internacionalización del universo científico es a la vez una internacionalización de la lengua y del léxico lingüístico. Sin embargo, aquellas reglas que son válidas para la formación del léxico científico y el léxico terminológico, a veces no son por completo aplicables a la lengua literaria. Cuando Rakić pone en tela de juicio la estructura de la lengua serbia, él establece una modernidad en la interpretación de la traducción, como lo advierte Meschonnic (2004:85). Las interpretaciones y premisas sobre la traducción y el aspecto funcional de la lengua, la significancia de la ortografía, y el contenido léxico de Rakić son observaciones teóricas muy modernas y contemporáneas.

Desde el comienzo, Rakić trata dos vertientes importantes en la teoría de la traducción: la que se traduce y la que se somete a la interpretación del tipo de género textual. Rakić diferencia el texto que posee mayor grado de especialización científica en comparación con el texto de carácter literario. Entenido de esta manera, el cambio lingüístico (o léxico) puede ser una ventaja o una desventaja dependiendo del género textual. La abundancia del léxico ruso es constitutivo para la riqueza de la lengua literaria o eclesiástica, pero en el ámbito de la lengua científica no es relevante. De esta manera, Rakić indica que las relaciones funcionales pueden ser discriminatorias en la traducción (especialmente si se trata de traducción literaria $)^{14}$. A la vez Rakić, de manera indirecta, ofrece una imagen del desarrollo de la lengua serbia, incluyendo su fase de la redacción rusa del antiguo eslavo, de la redacción serbia del antiguo eslavo hasta llegar a la época moderna que incluye la influencia alemana, en la cual él escribe y traduce. Este acercamiento a la influencia de las lenguas mediadoras o terceras lenguas en la formación de la lengua propia se asemeja a la visión de Toury en los períodos de la rusificación, alemanización y al final de la anglización de la lengua hebrea hasta llegar su aspecto contemporaneo. Estas influencias a veces rellenan las lagunas en la lengua meta, y se demuestran

14 Subrayamos que Toury (2004:130) en su interpretación del término equivalencia no insiste en la equivalencia literal entre el texto fuente y el texto meta. Al contrario, se trata del concepto funcional-relacional; es decir de un conjunto de las relaciones que han sido identificadas como discriminatorias para las maneras adecuadas o no-adecuadas de traducción en el entorno cultural al cual se aplican. 
muy constitutivas no sólo para el nivel léxico de la lengua, sino también para la forma de algunos géneros literarios. Según Toury (2004:193), incluso las pseudotraducciones tienen un papel importante en la formación no sólo de la literatura nacional, y por consiguiente, las lenguas nacionales, sino en la cultura en general.

El texto mismo traducido por Rakić es un campo del cruce de las correlaciones sistémicas e históricas de las normas, todavía no determinadas, lo que se demuestra a través de su omisión en el uso de la letra " $h$ " al comienzo de las palabras o de las formas deícticas. Así, la lingüística y la estética de la traducción de Rakić es inseparable de su indagar teórico, y a la vez existe paralelamente con la continuidad histórica de la lengua a la cual traduce. Mencionaremos sólo unos ejemplos:

“ipokrizija“" en vez de "hipokriziju“" [hipocresía] (1874, p.229)

"idraulika" en vez de "hidrauliku" [hidráulica] (1874, p. 240).

"ipoteza zemljine rotacije" en vez de "hipotezu zemljine rotacije" [hipótesis de la rotación de la tierra] $(1874$, p. 240).

"pa uzeti gotovo izrađene izraze i definisati i"? en vez de "pa uzeti gotovo izrađene izraze i definisati $\mathrm{i} h$ ? " $[\mathrm{y}$ tomar las expresiones ya hechas y definirlas? ] (1871, p. IV )

"manastirski" en vez de "manastirskih" [monasterial] (1871, p.366)

Estos ejemplos de los textos traducidos por Mita Rakić son belle infidèle a la manera serbia, que han aparecido más en la ortografía que en el campo semántico de las palabras. Entre la norma de aceptabilidad (en el texto meta) y de adecuación (en el texto fuente), Rakić llevó a cabo su idea de belle infidèle respecto a la reforma de Vuk Karadžić y su regla normativa de establecer el habla del este.

Toda la nota preliminar de Rakić en la traducción de la Historia del desarrollo intelectual de Europa se puede entender como un texto traductológico que establece principios importantes en cuanto a las normas de traducción, al léxico del texto traducido, a las peculiaridades culturológico-históricas relevantes para el desarrollo de una lengua, a las posibilidades de recibir las influencias extranjeras, al tipo de género textual (literario, eclesiástico, científico), y en base a estos aspectos, a la aplicación adecuada de la terminología. 


\section{Bibliografía}

DREPER, DŽ.V. (1871): Istorija umnoga razvića Jevrope, sa ingliskog preveo Mita Rakić, Državna štamparija, Beograd, vol.1.

DREPER, DŽ.V. (1874): Istorija umnoga razvića Jevrope, sa ingliskog preveo Mita Rakić, Državna štamparija, Beograd, vol.2.

HURTADO, ALBIR, A. (1996): Didáctica de la traducción, Publicaciones de la Universidad de Jaume I, Castellón de la Plana.

HURTADO, ALBIR, A. (2011): Traducción y traductología. Introducción a la traductología, 5 ed., Ed. Cátedra, Madrid.

IVIĆ, P. (1998): Pregled istorije srpskog jezika, priredio Aleksandar Mladenović, Izdavačka knjižarnica Zorana Stojanovića, Sremski Karlovci-Novi Sad.

KASTELAR, E. (1879): Narodni ljudi, s espanjolskog preveo Mita Rakić, Državna štamparija, Beograd.

KASTELAR, E. (1870): Beseda Emilija Kastelara o slobodi savesti španskih kortesa 23. aprila 1869, prevod Svetozar Savković, Platonova štamparija, Novi Sad.

KOVIĆ, M. (2014): Političke ideje Jovana Skrelića: pogled iz 2014. godine, Letopis matice srpske, libro 494, cuaderno 4, pp.465-472

MEŠONIK, A. (2004): Od lingvistike prevođenja do poetike prevođenja, prevele Bojana Anđelković i Zorana Đaković, dvojezično izdanje, AAOM/RAD, Beograd.

MILANOVIĆ, J. (2007): Aćim Čumić: 1836-1901, Zavod za udžbenike, Beograd.

MILIĆEVIĆ, M. Đ. (1901): Dodatak pomeniku do 1888. godine, Čupićeva zadužbina, Beograd.

STANOJEVIĆ, ST. (ed.) (1928): Narodne enciklopedije srpsko-hrvatskoslovenačke, vól.3. (N-R), Bibliografski zavod, Zagreb. Odrednica: „Rakić Mita“, p.799

NEJLOR, K.E.(1996): Sociolingvistički problemi među jezicima Južnih Slovena, preveo i priredio Miroljub Joković, Prosveta, Beograd.

NOVAKOVIĆ, S. Referati (predgovor u vidu referata) (1877) en: RAKIĆ, M.: Jedan list iz socijalne fizike, Državna štamparija, Beograd, pp.V-XI

ORTEGA I GASET, H. (2010): „Dve velike metafore“, prevela Jasmina Lazić, Mostovi, núm. 147, cuaderno 1, Beograd, pp.212-222

RAE, (2001): Diccionario de la lengua española, tomo I, vigésima primera edición, Espasa Calpe, Madrid. 
RAKIĆ, M. „Predgovor“ (1871): en: DREPER, DŽ. V. Istorija umnoga razvitka Jevrope, Državna štamparija, Beograd, vol.1, p. I-VII

RAKIĆ, M. „Štamparske pogreške“ (1871) en: DREPER, DŽ. V., Istorija umnoga razvitka Jevrope, Državna štamparija, Beograd, vol.1, p. 364-369.

RAKIĆ, M. (1877): Jedan list iz socijalne fizike, Državna štamparija, Beograd. SKERLIĆ,J.(1906):Omladina i njena književnost (1848-1871), izučavanje o nacionalnom i književnom romantizmu kod Srba, Srpska kraljevska akademija, Beograd.

TOURY, G. (2004): Los estudios descriptivos de traducción y más allá. Metodología de la investigación en estudios de traducción, Madrid, Cátedra.

VV.AA. (2011): Srpska bibliografija: Periodika 1768-2005, Narodna biblioteka Srbije, Beograd.

Jasmina Lazić

\section{Summary}

\section{TRADUCTOLOGICAL IDEAS OF MITA RAKIĆ}

Our objective in this paper is to present the traductological ideas of Mita Rakić (1846-1890), a member of the Serbian intellectual society, writer, philosopher, translator of several foreign languages, and translator of republican writers such as Victor Hugo and Emilio Castelar in the Serbian culture. In the first part of the paper we present the bibliographic references related to the life of Mita Rakic as well as his ideological and intellectual position at the end of XIX century. In the second part of the paper, we expose his traductological ideas given in the preface of the "History of the intellectual development of Europe" of John William Draper as an example of modern thought related to key themes in the contemporary translation theory such as: the authority of translation texts, the ideas that are needed to be translated from one culture to another, a connection between language (and its stadium of development) and translation; a critical attitudes towards incompetent translators, a textual gender of translated texts, an importance of translated texts to the development of language itself and at the same time establishing translation norms. Therefore, there are two sides of the importance of Mita Rakic's work: one is a historical-cultural perspective of introducing Emilio Castelar and Victor Hugo in Serbian culture which coincide with the period of establishing governmental institution such as a parliament during Obrenovic's monarchy and the other is rethinking some important issue regarding fundamental translation postulates.

Key words: critics and theory of translation, Mita Rakić, linguistic criticasters, textual gender (scientific, philosophical, literary) in translation. 